\title{
Ubiquitous Mobile Sensing for Water Quality Monitoring and Reporting within Lake Victoria Basin
}

\author{
Anthony Faustine, Aloys N. Mvuma \\ The University of Dodoma, Dodoma, Tanzania \\ Email: sambaiga@gmail.com, anmvuma@gmail.com
}

Received 3 October 2014; revised 1 November 2014; accepted 3 December 2014

Copyright (C) 2014 by authors and Scientific Research Publishing Inc.

This work is licensed under the Creative Commons Attribution International License (CC BY). http://creativecommons.org/licenses/by/4.0/

cc) (i) Open Access

\begin{abstract}
As the human population growth and industry pressure in most developing countries continue to increase, effective water quality monitoring and evaluation has become critical for water resources management programs. This paper presents the ubiquitous mobile sensing system for water quality data collection and monitoring applications in developing countries. The system was designed based on the analysis of the existing solution. Open source hardware and software was used to develop the prototype of the system. Field testing of the system conducted in Nkokonjero, Uganda and Mwanza, Tanzania verified the functionalities of the system and its practical application in actual environment. Results show that proposed solution is able to collect and present data in a mobile environment.
\end{abstract}

\section{Keywords}

\section{Arduino, Android, Ubiquitous Mobile Sensing, Water Quality}

\section{Introduction}

The rapid development of society, economy and an increasing number of human activities in most developing countries speed-up contamination and damage to the water resources. As the result monitoring of water quality is essential in order to characterize water and identify changes or trends in water quality over time [1]. For decades, water quality monitoring and evaluation have depended on a low-resolution water quality monitoring. This approach is time-consuming and expensive and not appropriate for certain biological and chemical processes such as oxidation-reduction potential that need to be measured on-site to ensure accuracy [2]. Recently, Wireless Sensor Networks (WSN) have received considerable attention in water quality monitoring and control applica- 
tions [3]-[7]. However, the practical application of WSN in water quality monitoring in developing countries is limited by following factors: 1) The initial investment cost of the WSN is considerably higher; 2) Physical security of the WSN nodes is also a challenge and 3) The sensor nodes are static over one particular location.

On the other hand, the rapid spread in mobile phone use in developing countries has increased the application of mobile data management [1]. Smart phones are becoming pervasive computing and communications platform [8]. The variety and number of mobile applications has also increased in recent years. This is because mobile phones are cheap, easy to use and can transmit multiple types of information including images and GPS points over long distances. The development and deployment of ubiquitous mobile sensing systems has become significant. However, the number of applications that leverage external sensing devices in water resources management is limited. The work presented by Aquaya [9] describes a water quality reporter system for data collection using featured phone. However, it doesn't provide the means to transfer the same data electronically to a central system and lacks sensing capability.

The use of ubiquitous sensor technologies and mobile data applications can improve the efficiency and accuracy of data reporting in the water sectors. This works extends the use of ubiquitous mobile sensing technologies by designing and developing mobile data capture and reporting applications that leverage external sensing devices in water resource management. It further discuses the role of this application in water quality management in rural and under-resourced areas in developing countries.

\section{System Design}

\subsection{System Architecture}

The proposed design for the Ubiquitous mobile Water quality Reporting system (u-WQR) for on-site sensing and reporting water quality data is presented. This system was developed as one component of the water governance system (WaGoSy) [10] designed to address water governance challenges around Lake Victoria Basin. Although more advanced techniques and technologies are already present in the world, u-WQR system is implemented using simpler and open source technology to reduce the system costs.

u-WQR system consists of four main components: 1) Ubiquitous Sensing Device (USD) which consists of Arduino microcontroller and sensor unit, 2) Communication module which connect the sensing device and the Android mobile phone, 3) The mobile application developed using the Android platform and 4) The WaGoSy web server. The Arduino microcontroller is the main controller that control and performs the necessary actions that need to be carried out by the system. The sensors and communication modules are directly interfaced to the main controller. The Arduino microcontroller communicate with mobile phone through a serial Bluetooth module. An overview of the proposed system architecture is shown in Figure 1.

\subsection{Software Development of the $u-W Q R$ Mobile Application}

Several platforms such as Windows Mobile, Symbian, iOS and Android can be used in the development of smart phone applications. The proposed u-WQR mobile application is developed using the Android platform. This is because Android platform is open source, supports background processes and rich inter-application communication and support most of the phones and handy devices on a market [8] [11]. Android Studio version 0.8.9 has been used for the development and implementation of the u-WQR mobile app. This is Android development environment based on IntelliJ IDEA [12].

The screenshots of the u-WQR mobile app developed is shown in Figure 2 while the processing of the u-WQR mobile app is shown in Figure 3. The designed mobile app for the water quality reporting system provide, user authentication, serial Bluetooth connection to the USD, remote connection (via internet) to the WaGoSy web server and history of the data reported. To successfully connect and access the u-WQR the user has to enter the correct user name and password as shown in Figure 3. The u-WQR mobile app is locally developed using open source and freeware development tools.

\subsection{The Proposed Ubiquitous Sensing Device}

The ubiquitous sensing device (USD) consists of Arduino microcontroller, sensor unit and power supply. The sensor unit as shown in Figure 4, consists of several sensors used to detect water quality parameters. Four types of sensor $\mathrm{pH}$ sensor, electrical conductivity sensors (EC), oxidation reduction potential (ORP) and temperature 

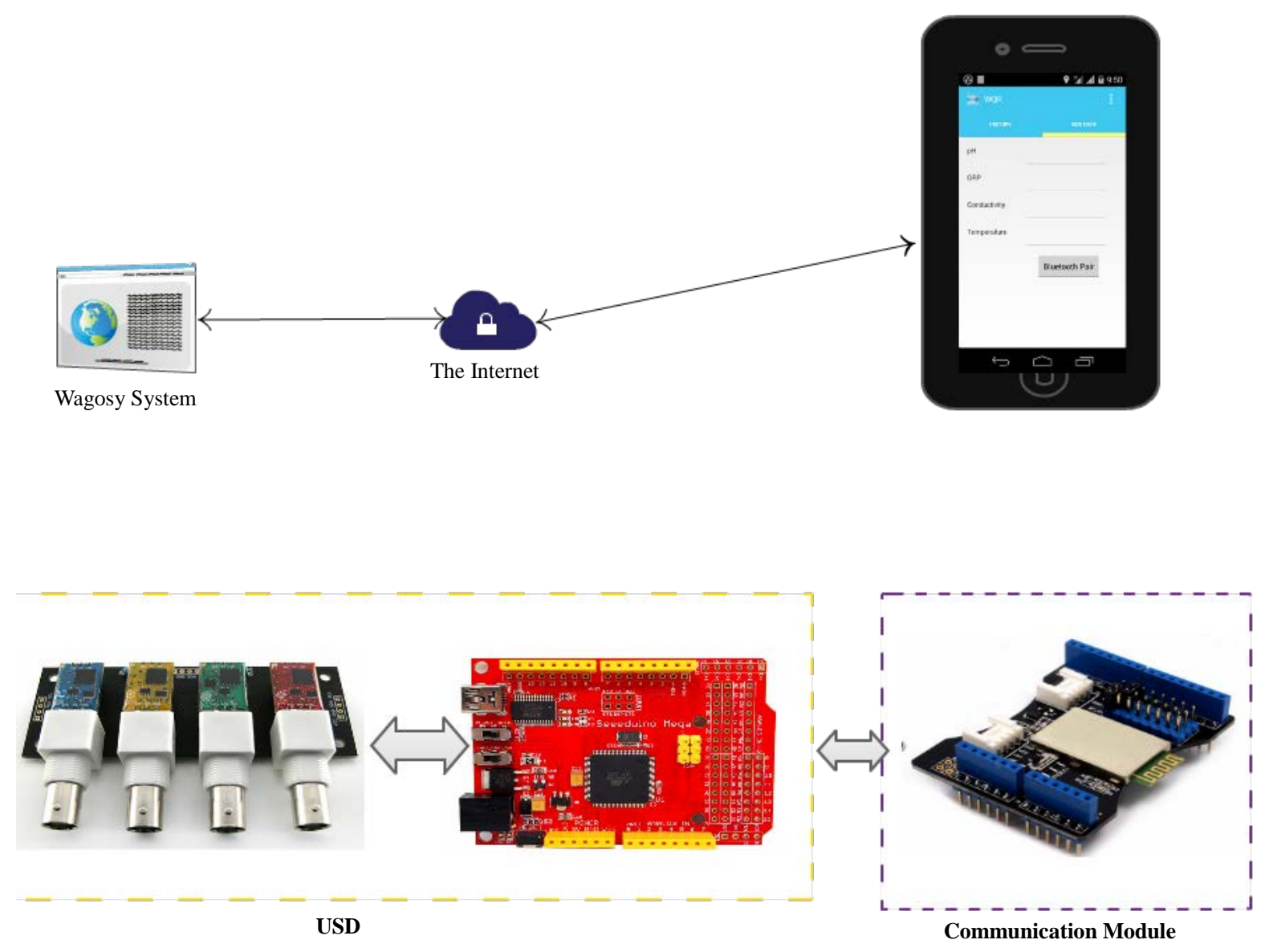

Figure 1. u-WQR system architecture.

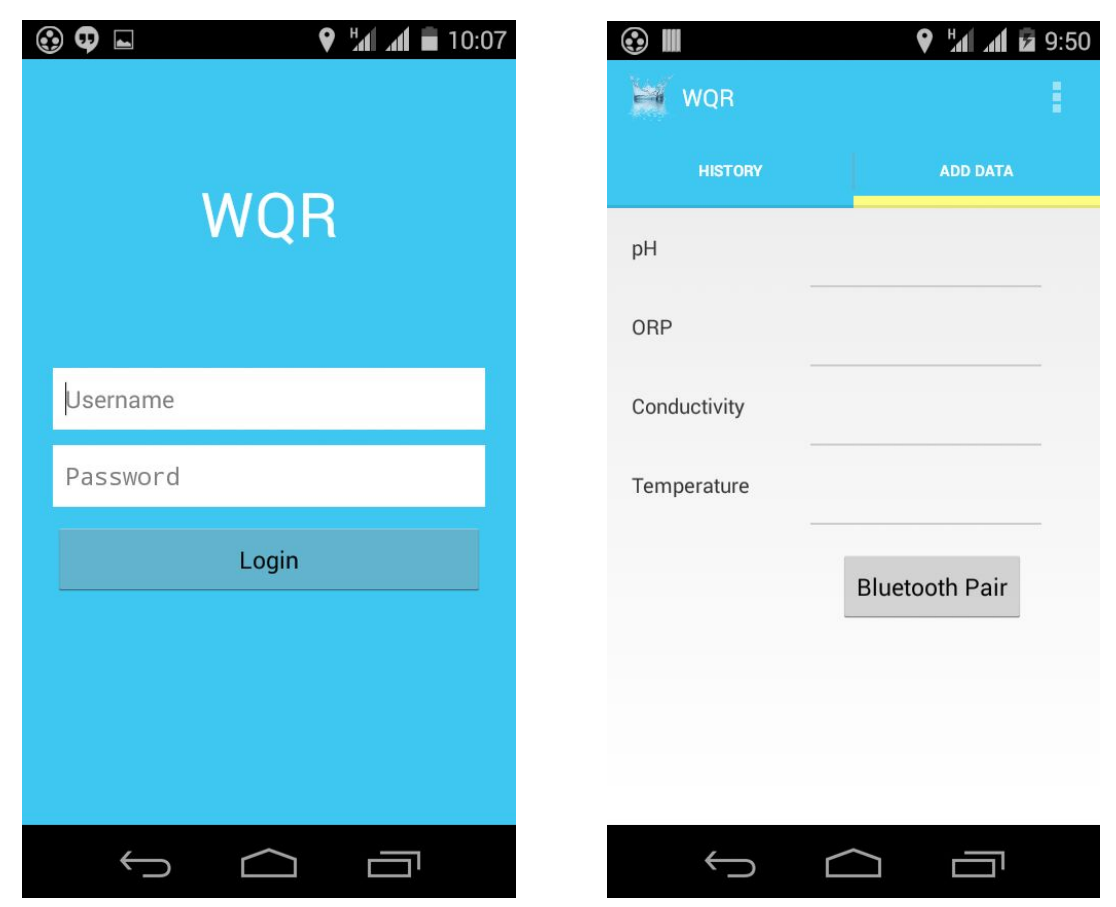

Figure 2. Screenshot of the proposedmobile app. 


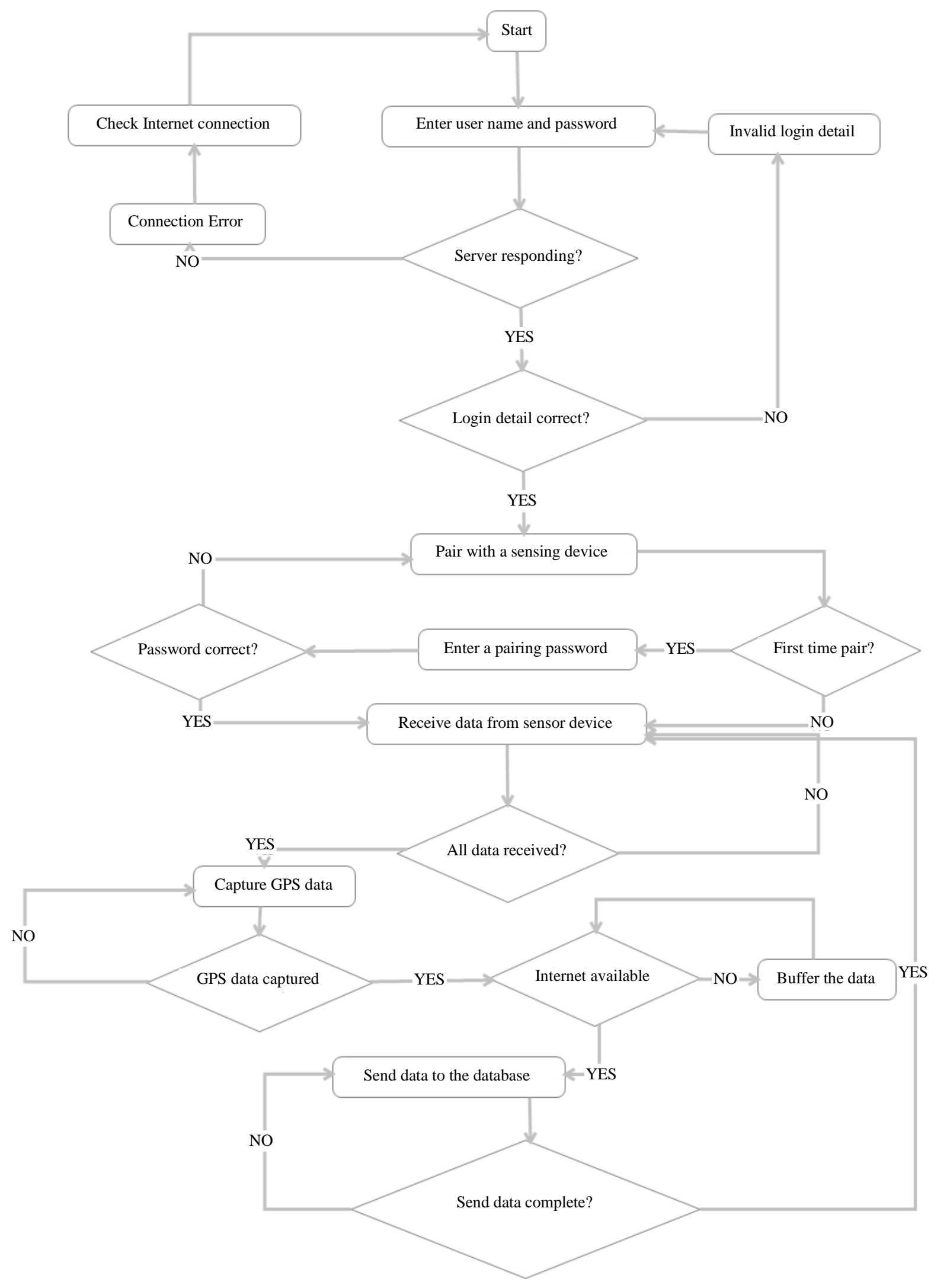

Figure 3. General processing of the proposed mobile app. 
sensor are used to provide general characterization of water quality. Specification for these sensors is summarized in Table 1. The EC, pH and ORP sensors are interfaced to the microcontroller using their respective circuit from Atlas scientific with exception of the temperature sensor which is directly connected to the microcontroller. To connect all the sensors to the Arduino, multi circuit I2C carrier board Atlas scientific is used. The sensors were accurately calibrated to ensure that they operate correctly.

The process of acquiring data from sensors is shown in Figure 5. Seeeduino Mega [13] from Seeedstudio is used to acquire and process sensor data from the sensor unit. This microcontroller is derived from Arduino Mega and is based on the ATmega 256 having 70 digital input/output pins. In this work 3.7 V 6AH rechargeable polymer lithium ion battery is used to power this USD. The battery has longer life and excellent long-term and self-discharge rates. However it provide less than $5 \mathrm{~V}$ required by most components on the USD. As the result the LiPo Rider Pro [14] is used to boost the output from a battery voltage to 5 V. LiPo Rider Pro, further allows to charge the lithium battery through USB.

\subsection{The Proposed Communication Module}

The recently announced Android Open Accessory Protocol (AAP) from Google allows external sensors to interact with an Android-powered device in a special accessory mode [8]. To use this approach to connect Arduino and the mobile phone you need to implement USB Host stack on the Arduino board. However, the device board is more complicated as it must provide power for both devices. The USB host API of Android can also be used to enable Arduino board to interact with an android device. With this solution the device board is very simple but works only with Android devices that have an USB Host port.

In addition, there are APIs to access the Bluetooth, Wi-Fi, and Near Field Communication (NFC) radios on Android devices. These communication APIs allow Android devices to connect to an even wider variety of external sensors. However, building applications that utilize external sensors is relatively complex from the application developers' perspective [8].

In this work, a serial Bluetooth module is used to provide communication between USD and the u-WQR mobile app. This is because Bluetooth is a popular method of communication between devices. Many smart phones today have the capability to communicate using Bluetooth and it is also easy to get cheap Bluetooth radio. The Bluetooth Shield from Seeedstudio is used to implement a communication. This shield integrates a serial

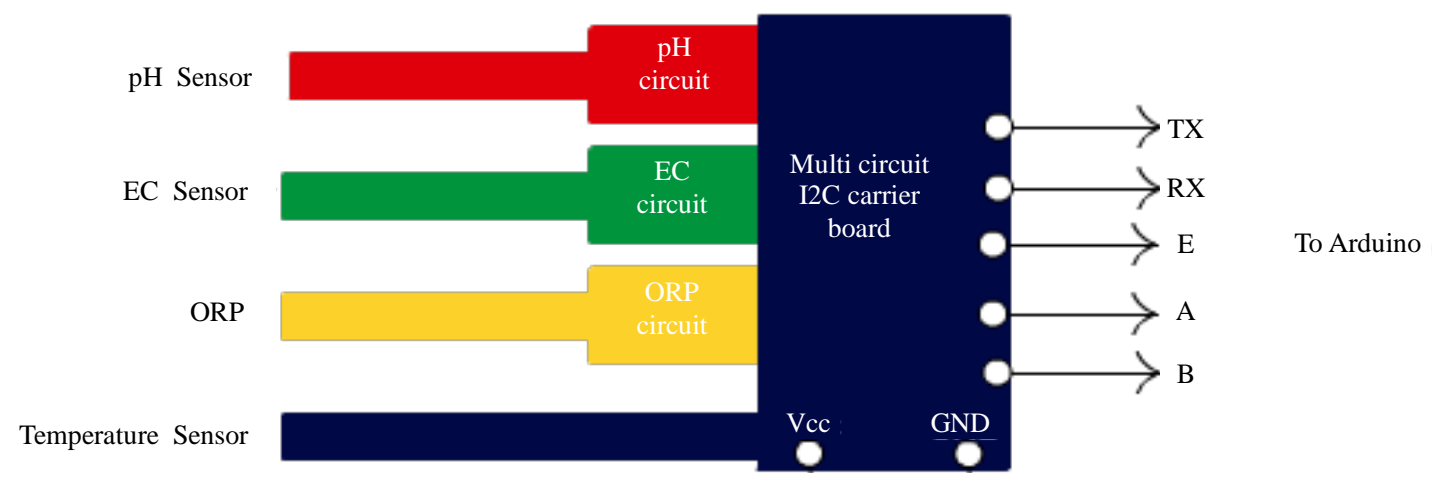

Figure 4. Sensor unit.

Table 1. Sensor specification.

\begin{tabular}{cccc}
\hline Sensor & Manufacture & Model & Range \\
\hline $\mathrm{pH}$ & Atlas Scientific & ENV-40-pH & $0-14\left(\mathrm{Na}^{+}\right.$error at $\left.>12.3 \mathrm{pH}\right)$ \\
$\mathrm{EC}$ & Atlas Scientific & ENV-40-EC-K0.1 & $(\mathrm{K}=0.1) 0.1-0.5 \mu \mathrm{s} / \mathrm{cm} \mathrm{to} 50,000 \mu \mathrm{s} / \mathrm{cm}$ \\
ORP & Atlas Scientific & ENV-40-ORP & $+/-2000 \mathrm{mV}$ \\
Temperature & Maxim Integrated & DS18B20 & $-55^{\circ} \mathrm{C} \mathrm{to}+125^{\circ} \mathrm{C}$ \\
\hline
\end{tabular}




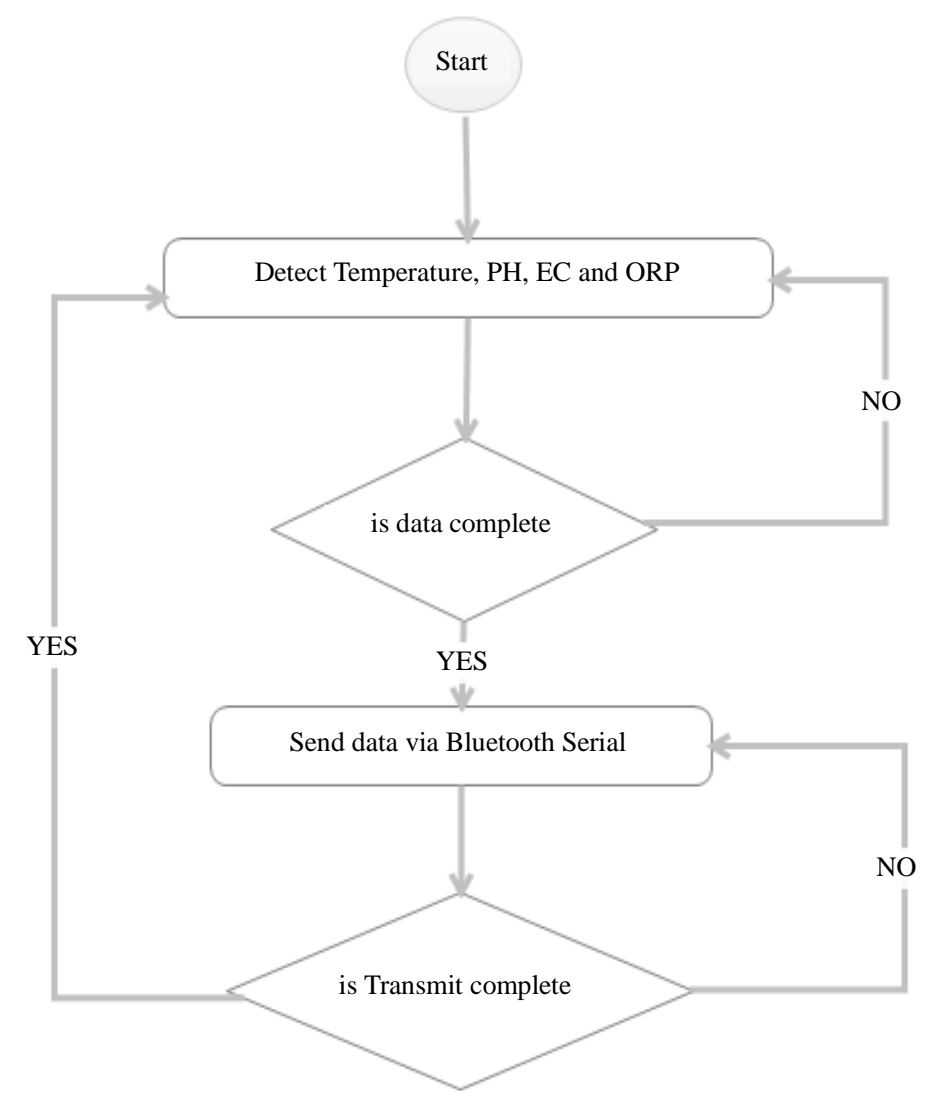

Figure 5. General processing of the proposed USD.

Bluetooth module which can be easily used with Arduino for transparent wireless serial communication. This module has two modes: master and slaver device and it is configured to operate in master mode in the proposed system.

\section{Results and Discussion}

The ubiquitous mobile sensing for water quality test and reporting system proposed in this paper was fully developed and tested to demonstrate its feasibility and effectiveness. Figure 6 show the complete u-WQR system during field test. The proposed system has all the necessary feature for mobile data reporting in water quality management applications. It allows decentralized actors to submit water source monitoring data via cell phones to a central database. The system provides visualization module which enable administrator to visualize the datasets. Users can view different parameters of water quality data from different locations in graphical forms as shown in Figure 7. From the graphs, user can observe the behavior of each parameter and alert the public in case of abnormality. The system can be configured to send SMS and or email alerts to managers when data reveal problems. The system total cost including sensing device, mobile phones and the Bluetooth module stands at $\$ 750$.

Field testing of the system conducted in Nkokonjero, Uganda and Mwanza, Tanzania verified the functionalities of the system and its practical application in actual environment. Through pilots in these two sites we have identified opportunities and challenges associated with the implementation of the u-WQR system in developing countries. For example, we noted that mobile data coverage is weak in many rural areas which limit instant data delivery. The system has a distinct advantage over traditional paper based reporting. Since it use electronic data collection which is relatively inexpensive, allow a well-coordinated and continuous monitoring of water quality from remote locations to centralized managers. Most stakeholders find the u-WQR system easy to use and require little training. On the other hand administrators and government authority managers were excited to see this system in place. 

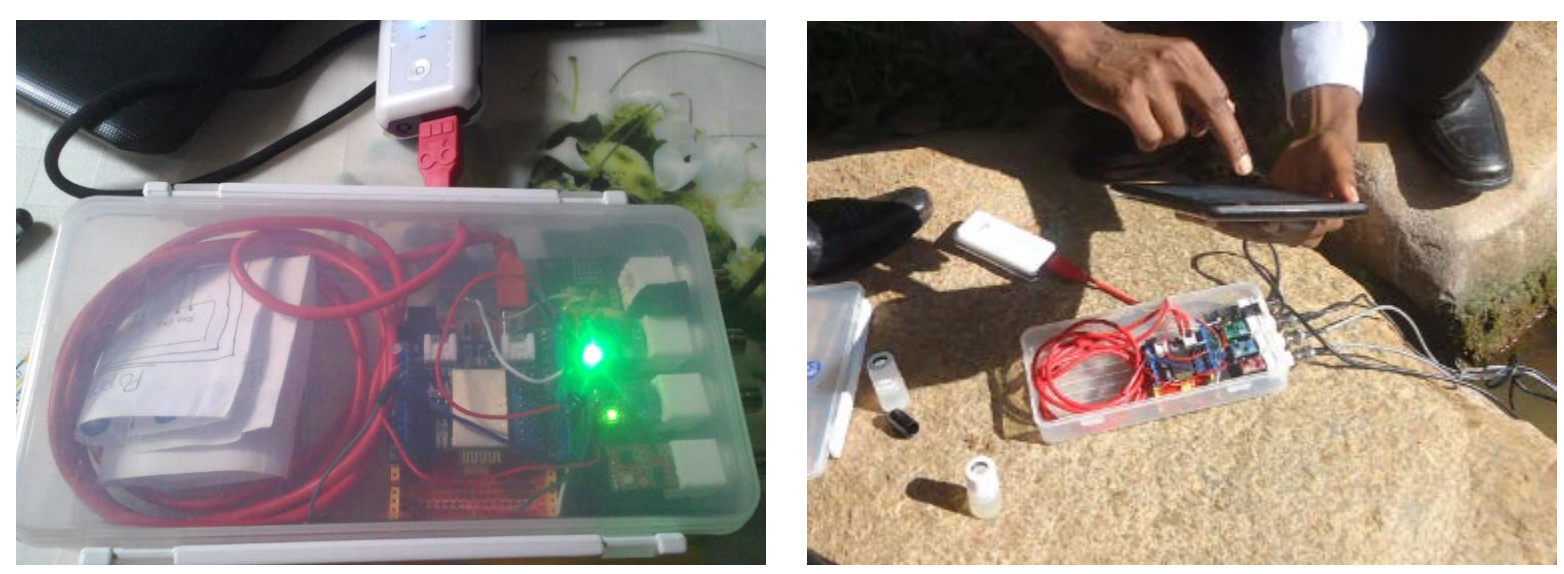

Figure 6. Field test of the u-WQR sytem.

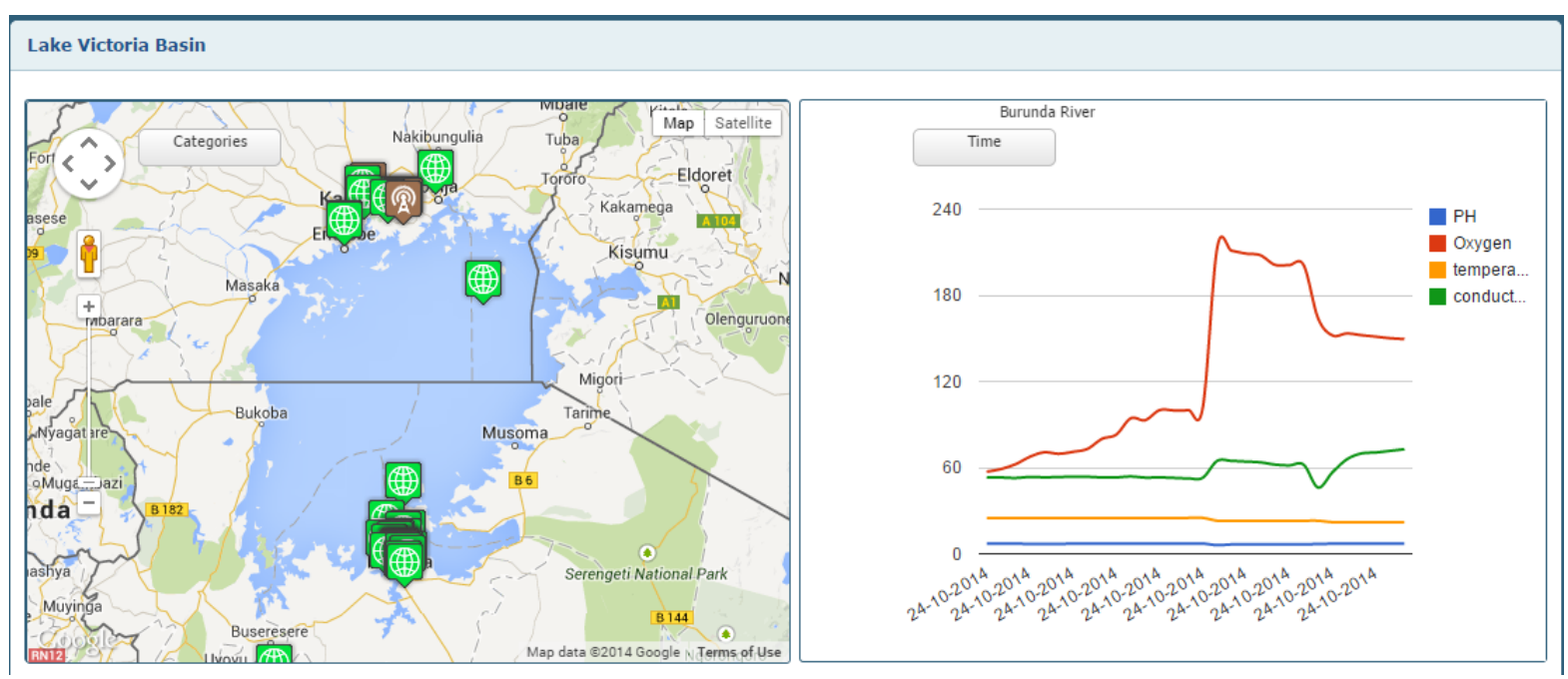

Figure 7. Visualizations of the u-WQR data.

\section{Conclusion}

The objective of the work presented in this paper was to realize the ubiquitous mobile sensing system for water quality monitoring and reporting. The system has been successfully designed and prototyped to capture and report the water quality parameters using an Android Bluetooth-enabled phone and Arduino based sensor device. The use of ubiquitous mobile sensing application in water quality monitoring and reporting has important implications for water resources management programs in developing countries. Prospective future works include incorporating water image processing and stabilizing the sensor device for field data collection.

\section{Acknowledgements}

Research team acknowledges Lake Victoria Research Initiative (VicRes), Inter-University Council for East Africa (IUCEA) and Swedish International Development Agency (SIDA) for supporting the research of which this paper is one of the outputs. The team also acknowledges the kind and material support received from stake-holders at different levels in the Lake Victoria Basin during the entire period of the research. The team wishes to thank the management and staff of Busitema University, Kigali Institute of Science and Technology and the University of Dodoma for their administrative support.

\section{References}

[1] DHI GRAS (2014) Water Quality Monitoring from Space, Baselines and Up-to-Date Information. 
http://worldwide.dhigroup.com/

[2] Rao, A.S., Gubbi, J. and Palaniswami, M. (2013) Design of Low-Cost Autonomous Water Quality Monitoring System. Advances in Computing, Communications and Informatics (ICACCI).

[3] Xu, G., Shen, W. and Wang, X. (2014) Applications of Wireless Sensor Networks in Marine Environment Monitoring: A Survey. Sensors (Basel), 14, 16932-16954. http://dx.doi.org/10.3390/s140916932

[4] Zia, H., Harris, N.R. and Merrett, G.V. (2014) Water Quality Monitoring Control and Management Framework Using Collaborative Wireless Sensor Networks. Proceedings of the 11th International Conference on Hydro Informatics, New York City.

[5] Kumar, R.K., et al. (2014) Solar Based Advanced Water Quality Monitoring System Using Wireless Sensor Network. International Journal of Science, Engineering and Technology Research (IJSETR), 3, 385-389.

[6] Gokulram, K. and Dhakshinamoorthy, T. (2014) Intelligent Pollution Monitoring Using Wireless Sensor Networks. International Journal of Research in Engineering and Technology.

[7] Zennaro, M., et al. (2009) On the Design of a Water Quality Wireless Sensor Network (WQWSN): An Application to Water Quality Monitoring in Malawi. International Conference on Parallel Processing Workshops, 22-25 September 2009, Vienna, 330-336.

[8] Chaudhri, R., et al. (2012) Open Data Kit Sensors : Mobile Data Collection with Wired and Wireless Sensors.

[9] Aquaya (2013) Testing the Tests: Aquaya Evaluates Aquatest on a Global Scale. http://www.aquaya.org/testing-the-tests-aquaya-evaluates-aquatest-on-a-global-scale/

[10] Wagosy System. http://wagosy.com/

[11] Kumar, S. (2014) Ubiquitous Smart Homes System Using Android Application. International Journal of Computer Networks \& Communications (IJCNC).

[12] Android Studio. https://developer.android.com/sdk/installing/studio.html

[13] Seeedstudio. Seeeduino Mega. http://www.seeedstudio.com/depot/Seeeduino-Mega-p-717.html

[14] LiPo Rider Pro. http://www.seeedstudio.com/wiki/index.php?title=Lipo_Rider_Pro 
Scientific Research Publishing (SCIRP) is one of the largest Open Access journal publishers. It is currently publishing more than 200 open access, online, peer-reviewed journals covering a wide range of academic disciplines. SCIRP serves the worldwide academic communities and contributes to the progress and application of science with its publication.

Other selected journals from SCIRP are listed as below. Submit your manuscript to us via either submit@scirp.org or Online Submission Portal.
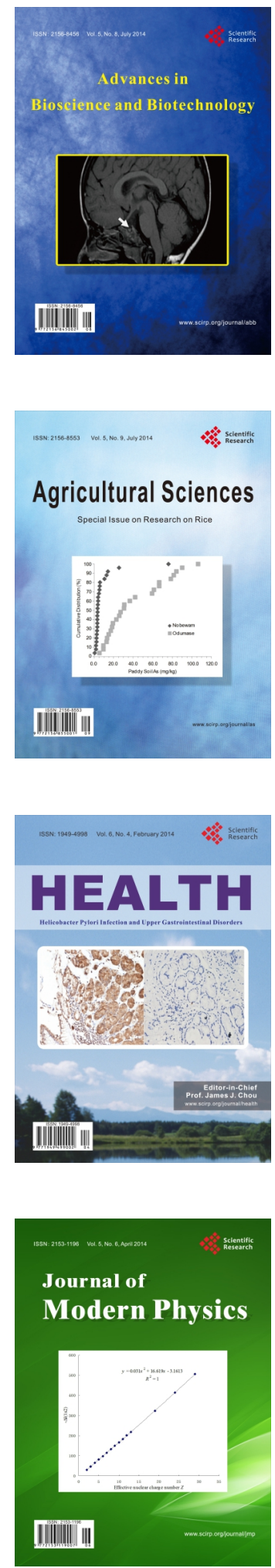
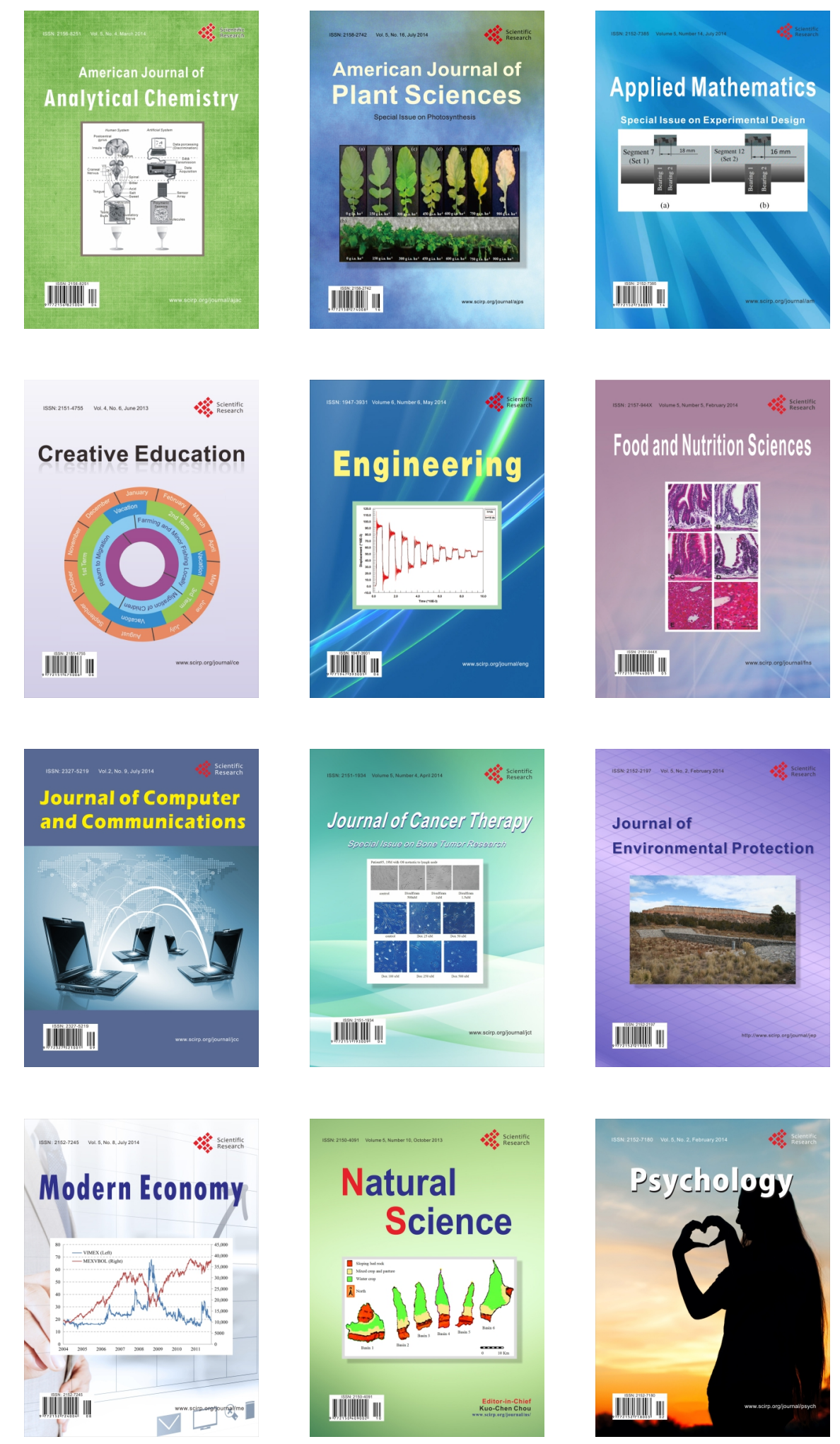